\title{
Philtrum length and intercommissural distance in newborn infants
}

\author{
YAKOV SIVAN, PAUL MERLOB, AND SALOMON H REISNER \\ From the Department of Neonatology, Beilinson Medical Center, Tel-Aviv University Sackler School \\ of Medicine, Petah-Tiqva, Israel.
}

SUMMARY In order to define standards for philtrum length and mouth width in the newborn infant, 198 term and preterm infants ( 27 to 41 gestational weeks) were examined. In every case the gestational age was determined chronologically and clinically and the philtrum length and mouth width (oral intercommissural distance) were measured by two observers using standard measurement techniques. Normal values are presented by plotting the mean \pm 2 SD for each gestational week versus the gestational age.

Philtrum length and oral intercommissural distance are important in syndrome diagnosis in the newborn infant. Long philtrum is found in Williams syndrome, craniocarpotarsal dysplasia, Langer-Giedion syndrome, and other birth defects. A short philtrum is observed in Di George syndrome and Cohen syndrome. Wide mouth, expressed as long oral intercommissural distance, is found in Goldenhar syndrome and the $18 \mathrm{p}$ syndrome, while a small mouth (short oral intercommissural distance) accompanies craniocarpotarsal dysplasia, hypoglossia-hypodactyly syndrome, and trisomy 18 syndrome. ${ }^{1-3}$

On examination of the newborn infant, the clinical impression may be misleading and therefore should be validated by quantitative criteria. However, no normal values for term and preterm infants for these parameters are available, especially in relation to gestational age. Because of the potential diagnostic implications of these signs the present study was undertaken in order to establish normal standards for these parameters from 27 to 41 weeks' gestation.

\section{Material and methods}

The philtrum length and oral intercommissural distance of 87 term (48 male and 39 female) and 111 preterm ( 55 male and 56 female) infants between the gestational age of 27 and 41 weeks were measured. No congenital anomalies were observed in any of these infants. The gestational age was calculated from the first day of the last menstrual period. In

Received for publication 12 July 1982. every case clinical assessments of gestational age were performed by the Dubowitz scoring system ${ }^{4}$ and by examination of the anterior vascular capsule of the lens ( 27 to 34 gestational weeks). ${ }^{5}$ Whenever a difference of 2 weeks or more between the clinical and the calculated gestational age was found, the infant was not included in the study. All measurements were made between 36 and 60 hours of age by two physicians using a sliding caliper graduated in millimetres (Siber Hegner Maschinen GPM Anthropological Instruments, Switzerland).

The measurements were performed according to the recommended guidelines of Feingold et al. ${ }^{6}$ The philtrum length was measured from the base of the columella to the midline depression of the vermilion border. The mouth was measured from cheilion to cheilion. Both measurements were obtained while the child was at rest.

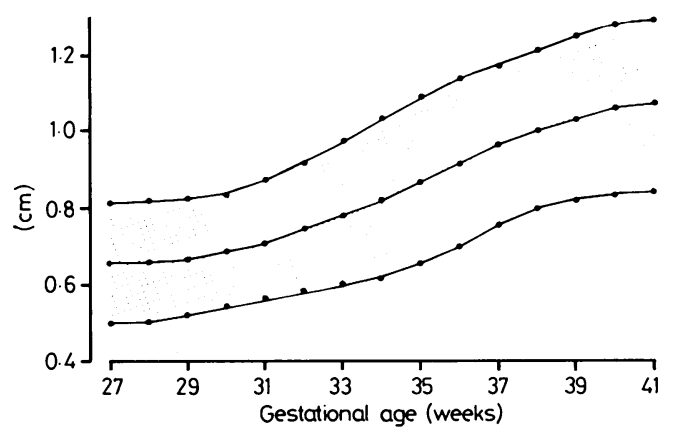

FIG 1 Philtrum length. The points represent the mean value $\pm 2 S D$ for each age group. 


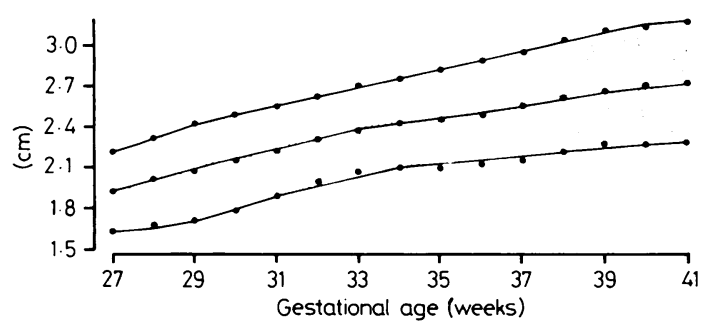

FIG 2 Intercommissural distance. The points represent the mean value $\pm 2 S D$ for each age group.

\section{Results}

No statistical difference was found between boys and girls and therefore the combined means \pm 2 SD are used. The distribution of values approximates a Gaussian curve. Normal values (mean \pm 2 SD) for philtrum length and intercommissural distance are depicted in figs 1 and 2.

\section{Discussion}

The purpose of this study was to assist the clinician in determining whether his newborn patient has an abnormal mouth opening or philtrum length. An optical illusion is produced by nasal length, width, or depth and by maxillar and mandibular structure. In examination of the newborn infant, use of the present data allows the clinician to discriminate between unusual features which may have distinct diagnostic implications, even in the very preterm infant. These measurements also provide information regarding the growth rate of these parameters during intrauterine development.

The authors are grateful to Dr Camil Fuchs and Pearl Lilos from the Statistical Consulting Unit, Tel Aviv University, for their statistical analysis.

\section{References}

1 Smith DW. Recognizable patterns of human malformation. 3rd ed. Philadelphia: Saunders, 1982.

2 Bergsma D. Birth defects compendium. New York: The National Foundation-March of Dimes, Alan R Liss, 1979.

${ }^{3}$ Goodman RM, Gorlin RJ. Atlas of the face in genetic disorders. 2nd ed. St Louis: Mosby, 1977.

4 Dubowitz LMS, Dubowitz V, Goldberg C. Clinical assessment of gestational age in the newborn infant. J Pediatr 1970;77:1-10.

5 Hittner HM, Hirsh NJ, Rudolph AJ. Assessment of gestational age by examination of the anterior vascular capsule of the lens. J Pediatr 1977;91:455-8.

6 Feingold M. Guidelines for clinical measurements In: Bergsma D, ed. Syndrome identification. Vol 3, No 2. New York: The National Foundation-March of Dimes, 1975.

Requests for reprints to Dr Yakov Sivan, Neonatal Department, Beilinson Medical Center, PetahTiqva, Israel 49100. 